\title{
The alliance of genes and environment in asthma and allergy
}

\author{
William Cookson
}

The diseases of asthma, eczema and hay fever are typified by reactions to common allergens, which are mediated by immunoglobulin E. These allergic diseases are increasing in prevalence, and are now a major source of disability throughout the developed world. They are the result of complex interactions between largely unknown genetic and environmental mechanisms. The identification of the environmental factors offers the real possibility of prevention of disease, and unravelling the genetics of allergic illnesses is likely to change their classification and treatment. Early life seems particularly important, when the initiation of allergic disease may result from genetic and environmental modification of the immune interaction between mother and child.

Allergies in one form or another affect a large part of humanity. 'Allergy ${ }^{*}$ ' was originally intended to mean 'deviation from the original state' when vaccination and injection with proteins and sera were seen to lead to a variety of harmful immune reactions ${ }^{1}$. The word 'atopy' (meaning 'strange disease') was coined to differentiate the familial syndrome of asthma and hay fever from these mixed reactions ${ }^{2}$. Infantile eczema has subsequently been recognized to be part of the same syndrome, and is often referred to as atopic dermatitis. Common usage has meant that the original broad meaning of allergy is lost, and the terms 'allergy' and 'atopy' are often used interchangeably, which has been the practice in this supplement.

Allergies are caused by the immune reaction to common inhaled proteins, known as allergens. Typical allergen sources include house dust mite, grass pollens and animal danders (sheddings from skin and fur). From a worldwide perspective it is the house dust mite that is of most importance to asthmatics. The total annual exposure of an individual to allergens is often only in the order of micrograms.

Allergens appear harmless in themselves, and only cause disease because of the intensity of the immune reaction which they provoke. This reaction is typified by immunoglobulin $E$ ( $\operatorname{IgE}$ ) responses against the allergen. IgE binds to its high-affinity receptor (FceRI) on mast cells and other effector cells. Exposure to allergen in a sensitized individual leads to crosslinking of IgE/Fc $\in$ RI complexes, which causes mast-cell degranulation and the initiation of inflammation.

The synthesis of IgE is under complex control, which is discussed in detail by Corry \& Kheradmand in this supplement. Interleukin (IL) -4 in particular is associated with upregulation of IgE, and interferon- $\gamma($ IFN- $\gamma$ ) with downregulation. The modulation and maintenance of inflammation may be carried out by mechanisms that are independent of the IgE/mast-cell axis.

The atopic state is recognized clinically by skin prick tests, in which allergen solutions are placed on the skin, and minute quantities of allergen are introduced into the epidermis by pricking with a needle through the solution. If IgE specific for the allergen is present, mast-cell degranulation takes place, with a resulting visible weal and flare (Fig. 1a). This early reaction resolves within tens of minutes, but it can be followed some hours afterwards with a late response, in which immune cells infiltrate into the skin. Both early and late responses are seen in the lungs and nose, when exposure to allergens induces the symptoms of asthma or hay fever. Many people who are atopic by skin tests do not have symptoms of allergic disease, indicating that factors other than the atopic state are important in causing asthma or eczema. Anaphylaxis is an extreme form of allergic reaction, in which systemic mast-cell degranulation

* Terms in italic are defined in the glossary on p. B39. takes place, followed by intractable bronchospasm, cardiovascular collapse and even death.

Atopic individuals can also be recognized by the presence of allergen-specific IgE in their serum, by elevations of the total serum $\mathrm{IgE}$, and by the presence of eosinophilia in their blood. These patterns are also seen in normal individuals who are suffering from parasitic infection, indicating that the processes of atopic inflammation evolved to deal with such infections.

\section{Asthma and eczema}

Asthma and eczema are the most serious of the allergic diseases. Asthma has become an epidemic, affecting 155 million individuals in the world. The cost of treating the disease is substantial. In the United States the figure approximates US\$6 billion dollars per annum $^{3}$, in Germany 5 billion DM (US $\$ 3$ billion) ${ }^{4}$, and in Britain $\mathfrak{E} 1$ billion (US\$1.6 billion) $)^{5}$. More than half of this expense is spent on hospital care and $80 \%$ of the entire bill is attributable to the $20 \%$ of patients who require the most treatment ${ }^{3}$. The market to the pharmaceutical industry for asthma medication is $\$ 5.5$ billion per annum ${ }^{6}$.

Asthma is an inflammatory disease of the airways of the lung (Fig. 1b). Narrowing occurs because of inflammation and mucous hypersecretion, and is exacerbated as the smooth musculature in the bronciolar walls becomes hyperresponsive to nonspecific stimuli. Intermittent airway constriction gives rise to the asthmatic symptoms of wheeze, cough, chest tightness and shortness of breath. Over time the bronchioles may become fibrosed or scarred, and the airflow limitation may become permanent.

Asthma is unlikely to be a single disease. Although most childhood asthmatics are also atopic, there is a wide spectrum of severity with mild intermittent wheezing lumped diagnostically with severe intractable disease. Adult-onset asthma is a poorly defined illness, which is more common in women and difficult to treat, and which in many cases does not seem to be atopic. Cigarette smoking is often a contributing cause. Other asthma syndromes, such as aspirinsensitive asthma and industrial asthma, may also operate through non-atopic mechanisms.

Eczema is as common as asthma, affecting between 10 and $20 \%$ of children in western populations $s^{7,8}$. It is characterized by an itchy red rash that has an easily broken surface and is primarily a disease of early childhood. It has a predisposition for flexures in the skin, such as at the front of elbows or behind the knees, but in severe cases the rash becomes generalized. There is a very strong association between atopic dermatitis and asthma, so that $60 \%$ of children attending a clinic for eczema may also have the other disease ${ }^{9}$.

\section{The nature of allergens}

The respiratory organs deal with a multitude of airborne particles, 
yet only a few of these particles from a limited number of sources consistently produce allergic reactions. Disease-associated allergens are usually soluble proteins. Most allergens have an enzymatic function in their natural state, but this is also true of most proteins, and a consistent activity shared by allergens has not been identified. Most allergens form particles of dimensions that allow them to become airborne and to penetrate the respiratory tree. Only a limited range of particle sizes are respirable, and are able to reach into the lung rather than being deposited in the nose and throat. It is still unclear whether the physical facts of allergens' ubiquity, respirability and solubility are sufficient to explain why they induce disease.

The allergens that most commonly produce reactions in susceptible individuals are known as 'major allergens'. Allergens are named according to their source and the order in which they were discovered. Major allergens from the house dust mite Dermatophagoides pteronyssinus, for example, include Der $p$ I and $\operatorname{Der} p$ II. Other important major allergens are Fel $d$ I from the cat Felis domesticus, Bet $v$ I from pollen of the birch tree (Betula verrucosa) and Phl $p \mathrm{I}$ and $P h l p \mathrm{~V}$ from the pollen of timothy grass Phleum pratense. Many other grass pollens, such as rye grass (Lolium perenne), have allergens that are similar to those of Phleum pratense (see ref. 10 for review).

Most common allergens have been extremely well characterized, with definition of the B- and T-cell antigenic determinants, and even the solution of the crystal structures (Fig. 2) ${ }^{10-12}$. This intimate knowledge of structure means that the tools now exist for the complete description for the events controlling allergen reaction with the immune system.

Particular allergens are associated with different types of allergic illnesses. Grass pollen allergens cause hay fever, and allergens derived from house dust mites, cats and cockroaches cause
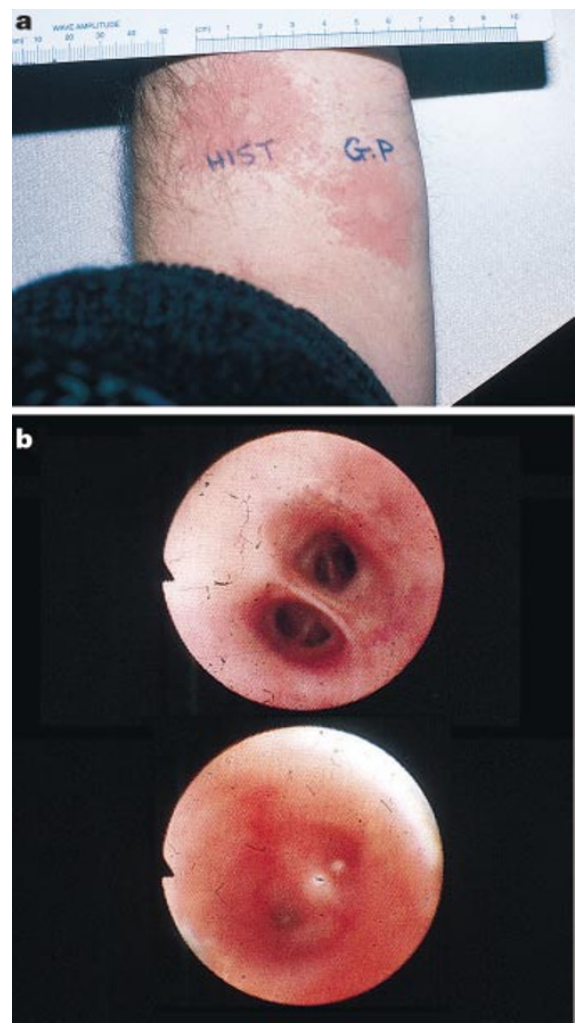

Figure 1 Consequences of allergic inflammation. a, Typical skin-test responses in an allergic subject, showing two wheals from grass pollen and histamine. b, Endoscopic appearances of an asthmatic airway, before and after local challenge with an allergen solution, showing inflammation in an asthmatic airway. (Courtesy of A. Frew.) asthma ${ }^{10}$. This difference is probably due to the physical dimensions of the particles, as pollen particles are relatively large and do not penetrate low into the bronchial tree. Children with eczema do not show a consistent pattern of allergen sensitization, but react to many allergens, including those derived from eggs, milk and cheese as well as the common airborne allergens. Transient IgE responses to food proteins are seen to a lesser degree in most children ${ }^{13}$, so sensitization to food allergens may be a nonspecific marker of a heightened allergic propensity. How either food or respiratory allergens induce disease in the skin is problematic, but a simple physical solution might be that children with eczema have delicate skin, and that allergens dissolve in highest concentrations in the moist flexural areas that show predilection to disease.

\section{The epidemic of asthma and atopic disease}

Asthma was quite rare at the beginning of the century, but its prevalence in developed countries has now risen to true epidemic proportions. Although some of the rising prevalence is possibly spurious and due to improvements in diagnosis and increased reporting of symptoms $s^{14}$, the evidence for changes in objective measurements of asthma-associated phenotypes is overwhelming $^{14-16}$. The number of children with diagnosed atopic dermatitis has doubled in the past 20 years ${ }^{15}$, and hay fever has shown a similar escalation in prevalence.

This increase in all atopic diseases can only be due to a factor or factors in the environment. The presence of the increase has a message of importance: identification of the responsible factors is very likely to make asthma and atopy preventable.

In the popular imagination, asthma is the result of air pollution. There is no doubt that air pollution with ozone and particulates can exacerbate existing asthma and precipitate hospital admission. However, pollution in most westernized countries has declined dramatically at the same time that the prevalence of asthma has been increasing.

Perceptions of the role of pollution in asthma changed with the work of von Mutius and her colleagues, who, once Germany was reunified, compared the prevalence of asthma in schoolchildren from the cities of Munich and Leipzig. The level of pollution was far higher in Leipzig, and the researchers expected to find a concomitant increase in asthma frequency. Surprisingly, there was significantly less allergic disease in polluted Leipzig than in clean Munich ${ }^{17}$. Subsequent studies showed that atopy, measured by skintest responses, was also less common in the east than in the west ${ }^{18}$. These findings have been mirrored by comparisons between other European populations ${ }^{19}$. In addition, the prevalence of atopy has risen steadily in east Germany as it has become more westernized ${ }^{20}$,

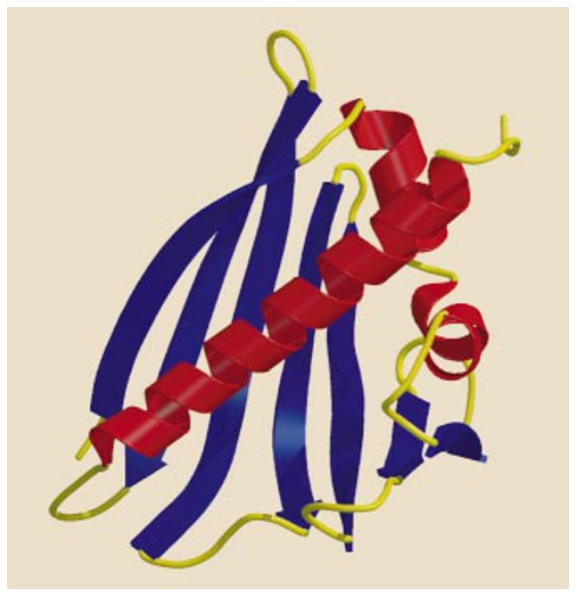

Figure 2 The crystal structure of the birch pollen allergen, Bet vl. (Courtesy of M. Gajhede.) 
Box 1.

\section{Epidemiological observations about asthma and allergy}

- There are tenfold regional differences in the prevalence of asthma and atopic diseases

- Allergic disease is more common in clean westernized environments

- Asthma and atopy are less common in the children of animal farmers

- Asthma and atopy are less common in younger siblings

- Asthma and atopy are less common in households with dogs as pets

although an increase in the prevalence of asthma is not yet evident. The results suggest that the increase in the prevalence of allergic disease is due to factors associated with a western lifestyle.

International studies of children ${ }^{21}$ and adults ${ }^{22}$ have shown substantial regional differences in the prevalence of atopic disease, indicating that epidemiological studies may be able to identify the factors predisposing to disease (Box 1). Asthma, diagnosed by questionnaire, is most common in children from Britain, Australia, New Zealand and the Republic of Ireland, and lowest in eastern Europe, Indonesia, Greece, China, Taiwan, Uzbekistan, India and Ethiopia $^{21}$. A rural lifestyle is protective both in Europe and Africa $^{19,23,24}$. Within Europe, the prevalence of atopic disease and atopic sensitization (measured by skin tests) is lowest in the children of farmers who keep animals near to the house $\mathrm{e}^{23,25}$. In non-farming households, the presence of a dog is also protective against disease ${ }^{26}$. There is an effect of birth order, with the youngest children of large sibships also being protected ${ }^{27}$, and the presence of an older brother being particularly effective $e^{22}$.

Events in early infancy are critical in determining the subsequent course of allergic disease. In the Scandinavian countries, a short intense spring flowering of birch trees is accompanied by symptoms in many individuals. Children born in the three months around the pollen season carry an increased risk of allergy to birch pollen for the rest of their life ${ }^{28}$. In English children the level of house dust mite in infants' bedding during the first year of life correlates with the subsequent risk of childhood asthma ${ }^{29}$.

The patterns of atopic disease could be explained by differences in the nature of childhood infection or changes in the bacterial flora of the bowel that follow from a clean western lifestyle ${ }^{17,19,30}$. It has been argued that our immune systems need to be taught, in the same way as our nervous systems ${ }^{31}$. We have co-evolved with our parasites and the constant threat of bacterial and viral infections, and now that infancies in the westernized world are largely free from such companionship, 'immune deviation' and allergic and other diseases may be the result. The cellular arguments behind this hypothesis are developed in the subsequent review in this supplement by Holt et al.

Epidemiology is a branch of medical science which moves slowly but with great force. The power of the epidemiological approach is exemplified by an investigation of outbreaks of severe life-threatening asthma in Barcelona ${ }^{32}$. Twenty-six circumscribed outbreaks took place between 1981 and 1986, filling the city's hospitals and causing several deaths. An epidemiological investigation was set up, which after examining many possibilities recognized that the cases of asthma were clustered near to the Barcelona harbour. The investigators looked for correlations between the type of products unloaded from ships and days in which outbreaks of asthma took place. All asthma-epidemic days in the years that they tested had coincided with the unloading of soybeans. The investigators also found that the wind conditions favoured the movement of air from the harbour to the city on every epidemic day. Finally, they tracked the source of the soyabean dust to a single harbour silo that lacked bag filters at its top.

Although the worldwide increase in the prevalence of asthma and allergies may not eventually be attributable to such a well defined source, the rich and varied pattern of prevalence of atopic diseases suggests that further epidemiological victories are possible.

\section{The genetic basis of asthma and atopic disease}

Asthma, eczema and the atopic state are strongly familial and have a genetic basis. Studies of twins have shown generally that concordance rates for asthma are significantly higher in monozygotic twins than dizygotic twins, and that the heritability of asthma may be as high as $75 \%$ (ref. 33). Analysis of the segregation of asthma within families indicates that asthma is influenced by a few genes with a moderate effect ('oligogenes'), rather than many genes of small effect ('polygenes') ${ }^{34-36}$. Twin studies of eczema in children have shown concordance rates of $77 \%$ and $15 \%$ in monozygotic and dizygotic twins, respectively ${ }^{37}$, indicating strong genetic effects on the disease. Parental eczema confers a higher risk of eczema in offspring than parental asthma or rhinitis ${ }^{38}$, suggesting the presence of eczema-specific genes. Analysis of the inheritance of the total serum IgE, which is the principal marker of the atopic state, has also suggested the presence of genes of strong effect ${ }^{39,40}$.

Given the likely presence of genes of strong effect, it is a reasonable expectation that understanding the genetics of both asthma and eczema will lead to improvements in their diagnosis, prevention and treatment. As a result, programmes aimed at the discovery of genes that predispose individuals to these illnesses are being carried out both within the industrial and the academic spheres.

Molecular genetics is about matching polymorphism in phenotype to polymorphism in the genetic material. Common diseases such as asthma are likely to be due to common variants ('alleles') in genes that alter gene functions in a subtle way rather than ablate gene function. This variation is as likely to be concentrated within the regulatory elements of the gene as within coding sequences.

Two general techniques are possible for identifying genetic effects on a disease. The first, known as the candidate gene approach, is to find polymorphism in a known gene and to compare the frequency of alleles in cases and controls. The second, and far more ambitious and expensive approach is that of positional cloning, which relies initially on linking the inheritance of specific chromosomal regions with the inheritance of disease ${ }^{41}$. Positional cloning has been extremely successful in identifying the genetic defects underlying single gene disorders, such as muscular dystrophy, cystic fibrosis and Huntington's disease. It is likely to make similar contributions to complex diseases such as asthma and atopy.

As a rule, academic groups are confined to the candidate gene approach because it is easier and cheaper, and industrial groups prefer positional cloning because it is systematic and because it has the ability to identify unexpected genes and mechanisms. In addition, the resources of industry allow the rational matching of the US $\$ 5.5$ billion annual market for asthma against the few million dollars required for gene discovery programmes.

\section{Candidate gene studies}

Although candidate gene studies may not find new genes, they still help the choice of targets for therapeutic intervention. Matching polymorphism in a candidate gene to a particular phenotype will demonstrate that interference with the action of this gene will produce a change in the phenotype. It will also show that the modulation of that gene's function is likely to be safe, because variation in this pathway has been encouraged in nature. The absence of polymorphism does not infer absence of a critical role in a particular pathway, but the corollary that conservation of response is important in evolutionary terms may be a warning against interference with a particular gene or pathway.

Several candidate genes have been implicated in allergic disease. The first effect to be recognized was the human leukocyte antigen (HLA) class II restriction of the response to particular allergens (Fig. 3). The strongest and most consistent association is between a minor component of ragweed antigen (Amb a V) and HLA-DR2. Many other possible positive and negative associations of the major 


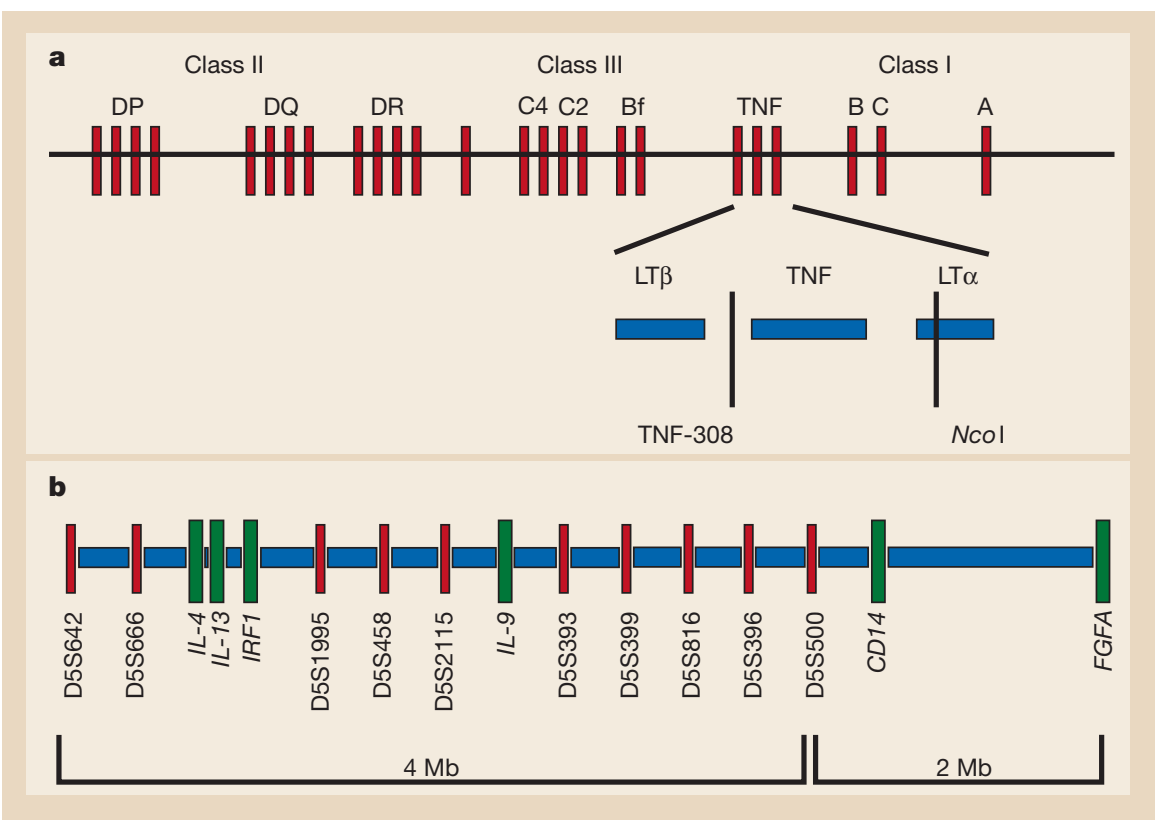

Figure 3 Gene clusters affecting allergic inflammation. a, The human major histocompatibility complex. HLA class II genes influence the ability to react to particular allergens, and TNF genes may modulate the intensity of airway inflammation independently of lgE responses. $\mathbf{b}$, The cytokine cluster on chromosome 5. Polymorphisms are recognized in several of these genes (including those encoding $\mathrm{L}-4$,
IL-13, IRF1, IL-9, CD14 and FGFA), which may modulate the intensity of the allergic response. It is possible that genes within the cluster are co-regulated to give a consistent individual pattern of cytokine expression. D5S numbers refer to anonymous microsatellite markers used in the genetic mapping of the locus. histocompatibility complex (MHC) with allergen reactivity have been described, most of which have not been confirmed (see ref. 10 for review). The overall effect of the MHC on allergens seems to be a multiplicity of small effects, usually conferring a risk factor less than twice as high as normal ${ }^{10}$. These results are unlikely to be useful clinically. Stronger HLA effects may be seen when the antigen is small and contains a single or very few antigenic determinants. This may be the case with aspirin-induced asthma and DPB1 ${ }^{\star} 0301$, and sensitivity to inhaled acid anhydrides and HLA-DR3 (ref. 10).

Linkage of atopy to a genetic marker on the long arm (q) of chromosome 11 at band 13 (11q13) was reported ten years ago ${ }^{42}$, and was followed by a protracted argument about the significance of results $^{43}$. The experience gained from the investigation of this particular locus illustrates how the problems of sample size and selection, replication of genetic linkage, parent of origin effects (discussed below), genetic heterogeneity, and phenotypic pleiotropy must be solved for the effective and systematic identification of the genes predisposing to the atopic disorders.

The beta chain of the high-affinity receptor for $\operatorname{IgE}(F c \in R I-\beta)$ was subsequently localized to the same region, and polymorphism with the gene related in different studies to atopy ${ }^{44}$, asthma ${ }^{45}$, bronchial hyperresponsiveness ${ }^{46}$ and severe atopic dermatitis ${ }^{9}$. Polymorphism within the gene has also been associated with levels of IgE in heavily parasitized Australian aborigines, implying a protective role for the gene in helminth infestation ${ }^{47}$. Although a few coding changes have been identified within $F c \in R I-\beta^{45,48}$, they are conservative and do not seem to alter gene function.

The Fc $\epsilon$ RI receptor acts as the allergic trigger on mast and other cells, and is central to the allergic response. Its biology is described in detail by Turner \& Kinet in the supplement. The $\beta$-chain is not essential for FceRI function, but it both augments the surface expression of the receptor, and acts as an amplifying element within it. Any variation in the level of the $\beta$-chain expression may therefore modify receptor function. The controlling elements of the gene are now under study for genetic polymorphism.

Several associations have been noted between measures of atopy and genes of the chromosome 5 cytokine cluster, including $I L-4$ and CD14 (refs 49, 50; Fig. 3). The congregation of cytokine genes in the region may have evolved for their co-regulation, and claims for the importance of particular polymorphisms within the cluster should be interpreted in the context of linkage disequilibrium with other markers and other known or unknown genes. An effect on atopy and serum IgE levels of $I L-4$ receptor (on chromosome 16) has been recognized $^{51}$, and may be stronger than the effects of polymorphism in $I L-4$ itself. Coding variants within the $\beta$-adrenergic receptor have been shown in vitro to be functionally important ${ }^{52}$, but associations with asthma have been weak and inconsistent ${ }^{53}$.

Tumour necrosis factor (TNF) is a pro-inflammatory cytokine that is abundant in asthmatic airways. An association between TNF alleles and asthma has been observed ${ }^{54}$ and seems independent of the serum IgE or other measures of atopy, illustrating that asthma is not the result of only allergic mechanisms ${ }^{54}$.

In general, these studies of candidate genes have been done on limited sample sizes. The next step in defining the utility of genetic polymorphisms in the clinical classification of asthma and allergies must be their application to large-scale epidemiological studies. It is also desirable to test sub-groups of allergic disease, such as children with severe illness, or illness that is resistant to treatment. In this context, the association of FceRI- $\beta$ polymorphisms with severe atopy, asthma, and eczema ${ }^{9,48,55}$ may eventually define a syndrome of early-onset severe allergic disease.

\section{Pharmacogenetics}

Individuals vary widely in their response to treatments with drugs. At present, optimal doses that balance side effects against therapeutic actions in a particular patient can often be determined only by trial and error. The study of pharmacogenetics may be able to use genetic polymorphism to predict the response of individuals to particular treatments. In the case of asthma, a variant within the promoter of the 5-lipoxygenase gene has recently been suggested to predict the response to the antileukotriene ABT-761 (ref. 56). A Leukotriene C4 synthase promoter polymorphism has been shown 


\section{Table 1 Genetic loci affecting asthma-associated phenotypes}

\begin{tabular}{lcc}
\hline Chromosome & Candidate genes & Authors \\
\hline 2 & $I L-1 . I L-1-R A$ & $71-73$ \\
5 & $I L-4, I L-13, I L-9$ & $62,63,73$ \\
$6 p$ & $M H C$ & $67,70,71$ \\
$12 q$ & $I F N-\gamma$ & $64,65,70$ \\
$13 q$ & & $67-70$
\end{tabular}

The loci presented in the table are those that have been identified consistently by genome screen and genetic-linkage studies Localizations in many regions are only approximate, and the regions of linkage may cover large areas. Definite co-localization awaits typing with the same markers in all panels of families.

to be associated with increased risk of aspirin-induced asthma, and may also predict the response to treatment ${ }^{57}$. It also seems possible that the polymorphisms in the $\beta$-adrenergic receptor regulate the response to the stock asthma treatment of $\beta$-adrenergic agonists. These results require confirmation and considerable extension, but may mark the beginning of the clinical use of genotyping as an adjunct to pharmacotherapy for asthma and many other disorders.

\section{Positional cloning studies}

Positional cloning is based on the study of families in which a particular disease or phenotype is transmitted to (or 'segregates' through) family members. The families are studied by visualizing nonspecific genetic polymorphisms that are in known positions on the chromosomes. These 'markers' typically contain repeat sequences of DNA, such as $(\mathrm{CA})_{n}$, which vary greatly between individuals and can differentiate between individual chromosomes in a family. Many thousands of such markers have been identified and integrated into a dense map that covers all chromosomes ${ }^{58}$.

Once markers have been typed, the families are examined to see if any of the markers is inherited in the same way as the phenotype of interest. When marker and phenotype are co-inherited, genetic linkage is said to exist. The decision about whether genetic linkage is real or not is highly statistical, and made more difficult when hundreds of markers and several phenotypes have been tested. Stringent criteria need to be applied in these circumstances, so that if a genome-wide search for linkage has been carried out, a probability of less than 0.0007 may only be 'suggestive' of linkage, and a significant' linkage may require a probability less than 0.00002 (ref. 59).

The discovery of genetic linkage usually means that a broad chromosomal region is likely to contain a gene influencing the disease phenotype. Saturation of the region with more closely spaced markers may reduce the interval for localization to between 5 and 30 million base pairs of DNA. Regions of this size will contain far too many genes to be studied in detail for effects on disease.

Happily, distinctive alleles of individual polymorphisms show non-random association with alleles of neighbouring polymorphisms in the DNA. This phenomenon, known as linkage disequilibrium, extends for far shorter distances than genetic linkage, and close localization of disease genes is likely to depend on the detection of linkage disequilibrium between marker alleles and disease phenotypes. The remaining intervals of 0.5 to 1.0 megabases can be then be dissected systematically.

The choice of phenotype is critical in determining the success of positional cloning. Atopic asthma is easily recognized clinically, and has an obvious familial clustering. For this reason, many genetic studies have concentrated on the asthma of childhood, and the underlying atopic state. The simplest type of genetic linkage study relies on families that contain two affected children. The assumption behind this approach is that environmental factors will have acted on both siblings, and may be discounted in the statistical analyses of data. Unfortunately, the high frequency of asthma and atopy in the population has adverse effects on the power to detect linkage to affected sibling pairs ${ }^{60}$. Simulation studies indicate that
Table 2 Coincidence of loci affecting asthma-associated phenotypes and other disorders

\begin{tabular}{|c|c|c|}
\hline Chromosome & Candidate genes & Diseases \\
\hline Chromosome 2 & IL-1 cluster & $\begin{array}{l}\text { Inflammatory bowel disease, } \\
\text { Rheumatoid arthritis }\end{array}$ \\
\hline Chromosome 6 & $\mathrm{MHC}$ & Multiple \\
\hline Chromosome 7 & & Inflammatory bowel disease \\
\hline Chromosome 11 & & Type I diabetes \\
\hline Chromosome 12 & $\mathrm{IFN}-\gamma$ & Inflammatory bowel disease \\
\hline Chromosome 14 & TCR- $\alpha$ & Rheumatoid arthritis \\
\hline Chromosome 16 & & Inflammatory bowel disease \\
\hline
\end{tabular}

500 affected sibling pairs will give less than $50 \%$ power to detect linkage to a given marker, and that over 1,000 affected pairs will be required to achieve $90 \%$ power. The use of quantitative traits underlying asthma together with selection for phenotypic discordance within families may be important if studies are to detect linkage with sufficient power to generate consistent findings ${ }^{60,61}$.

Despite these difficulties, several genetic regions have been identified consistently by different groups (Table 1). Regions studied because they contain important candidates include chromosome $5 \mathrm{q}$ (containing the $I L-4 / I L-9$ interleukin cluster) ${ }^{62,63}$ chromosome $12 \mathrm{q}$ (near the IFN gene) ${ }^{64,65}$ and chromosome $14 \mathrm{q}$ (near the TCR- $\alpha / \delta$ cluster) ${ }^{66}$.

Several genome-wide searches have been carried out. A search for quantitative traits underlying asthma identified significant evidence for linkage on chromosomes 4q, 6 (near the MHC), 7, 11q (containing FceRI- $\beta$ ), 13q and 16 (ref. 67). A replication sample of families in the same study confirmed linkage to chromosomes 4, 11, 13 and 16 (ref. 67). Linkage of the total serum IgE to a protein polymorphism on chromosome 13 had been identified several years earlier ${ }^{68}$, and linkage to the region has been again confirmed by a single locus study of Japanese families ${ }^{69}$. The same study identified potential linkage disequilibrium between disease and a particular marker ${ }^{69}$. A two-stage screen in Hutterite families from the United States found evidence for linkage in several chromosome regions, with replication for loci on chromosomes 5q, 12q, 19q and 21q (ref. 70). Linkage to $13 \mathrm{q}$ was seen in the first panel of families only. A screen in German families identified evidence for linkage to asthma on chromosomes 2q, 6p (near the MHC), 9 and 12q (ref. 71). A genome screen for responsiveness to house dust mite allergen found suggestive linkage to chromosomes 2q, 6p (MHC) and 13q, as well as chromosome 8p (ref. 72). A genome screen in American families from three racial groups found possible linkage to the same regions as other studies on chromosomes 2q, 5q, 6p, 12q, 13q and 14 $q$ (ref. 73). Several other possible loci were identified, but have not yet been confirmed. A two-stage genome screen in French families found replicated linkage on chromosomes $1 \mathrm{p}, 12 \mathrm{q}$ and $17 \mathrm{q}$ (ref. 74).

Genome screens have also been done by several industrial groups $^{6}$, the results of which remain secret. The replication of linkage results is necessary before committing to identifying genes across a large region. In these circumstances, the industrial instinct of secrecy may be counter-productive.

The data from all these studies indicate that chromosomes $2 \mathrm{q}, 5 \mathrm{q}$, $6 \mathrm{q}, 12 \mathrm{q}$ and $13 \mathrm{q}$ contain loci that consistently affect asthma and atopy with sufficient strength to be detected by genetic linkage. The challenge is to distil all this data and to refine the localizations sufficiently for gene identification to begin. This process would be helped by agreement between groups to saturate these regions with the same panels of markers, and to allow meta-analysis of the pooled data. Progress towards this goal has been taken by the agreement of some groups to pool data from chromosome 5 in the Consortium on Asthma Genetics (COAG) study.

Genetic studies of other disorders may also have an impact on asthma and atopy (Table 2). Crohn's disease and ulcerative colitis are inflammatory bowel diseases of unknown aetiology which show 
familial clustering. Genome-wide screens have implicated loci on chromosomes 3, 7, 12 and 16 (refs 75-77). The regions on chromosomes 7, 12 and 16 coincide closely with the asthma and atopy loci on the same chromosomes. Polymorphism in the $I L-1$ cluster on chromosome 2 has also been shown to influence the severity of inflammatory bowel disease ${ }^{78}$. A genome-wide screen in families with rheumatoid arthritis has similarly shown linkage near the asthma locus on chromosome 2 and the TCR- $\alpha$ locus on chromosome 14 (ref. 79). Linkage to type I diabetes is found near FceRI- $\beta$ on chromosome 11q13 (ref. 80). These findings indicate that important genes or gene families may be common to several inflammatory and immune disorders.

The practice of genetics is changing rapidly. The genome will be largely sequenced within a year, so that the painstaking construction of physical maps of individual regions will no longer be needed. The technology that allows the expression of thousands of genes to be measured simultaneously ${ }^{81}$ allows the facile observation that the expression of many genes differs between asthmatics and nonasthmatics. The sheer volume of nonspecific genes activated in any cellular process may limit the usefulness of this approach.

Genome-wide association studies that use the typing of thousands of single nucleotide polymorphisms (SNPs) have been proposed as a more powerful method of detecting genetic effects than linkage mapping ${ }^{82}$. This approach would seem to bring considerable difficulties of statistical analysis, if only for the need to apply a correction of more than 100,000 for multiple comparisons to each data point. Assumptions about the extent of linkage disequilibrium through the genome have yet to be tested in real data, and the effects of allele frequency on detection of linkage disequilibrium to disease alleles has not been investigated. Nevertheless, it is quite possible that expression studies and SNP mapping may form the bridge between localization to large regions and the identification of disease genes and their function.

\section{Maternal effects on asthma and allergic disease}

Many epidemiological studies have indicated that maternal phenotype influences the inheritance of asthma and allergy (ref. 83 for review), although in general the studies were not designed specifically to test for parent-of-origin effects. The presence of asthma, eczema, elevated serum IgE levels and positive skin-prick tests in children have all been accompanied by an increased prevalence of asthma or atopy in mothers ${ }^{83}$. The differential risk of transmission between parents is approximately fourfold. Parent-of-origin effects have been noted in other immunological disorders, most notably type I diabetes ${ }^{84}$, rheumatoid arthritis ${ }^{85}$, inflammatory bowel disease $^{86}$ and selective IgA deficiency ${ }^{87}$, indicating that parental effects on the developing infant's immune system may be an important common process.

The immune systems of the maternal-fetal unit operate in a narrow space between rejection and nurture, in which proteins derived from paternal genes may be differentially antigenic to those derived from maternal alleles. Two types of maternally driven mechanisms may possibly operate to control or modify the fetal immune system. First, the maternal effect might result from immune interactions between the fetus and the mother. Maternal-fetal immune interaction is well recognized, and takes place through the placenta as well as through breast milk (see review by Holt et al., this supplement). This interaction may have profound effects on the developing fetal immune system. Second, the maternal effect may be the result of genomic imprinting. Genomic imprinting is a process in which the allele from one parent is differentially expressed relative to the allele derived from the other parent ${ }^{88}$. Imprinting seems important when there is a conflict of interest between maternal and paternal genes, such as those that control fetal growth.

A window to the investigation of maternal effects may come from the observation that linkage of severe atopy to the $F c \in R I-\beta$ locus on chromosome 11q13 has been characterized by a maternal pattern, with linkage and association seen most strongly to maternally derived alleles ${ }^{89}$. A recent family-based study of association between the alleles of an FceRI- $\beta$ SNP and atopic eczema showed a highly significant transmission of one of the maternal alleles, with an intriguing suggestion that the same allele was protective when transmitted from the father ${ }^{9}$.

Genomic imprinting would lead in an unselected population to preferential maternal transmission of a disease-associated allele regardless of maternal phenotype. Investigation of the effects of parental phenotype on linkage of the total serum IgE to FceRI- $\beta$ has been done in families taken from a general population sample. Parents were classified as affected if their age- and sex-adjusted total serum IgE was above $70 \%$ of the population. Linkage to the locus was seen most strongly when the mother was unaffected, or when the father was affected ${ }^{90}$, which is not consistent with simple genomic imprinting. A maternal pattern of linkage to atopy does not seem to be confined to $F c \in R I-\beta$, and the phenomenon has been observed at loci on chromosomes 4 and 16 (ref. 67). These results also indicate that the maternal linkage is not due to a simple genetic mechanism at a single locus.

Parent-of-origin linkages operate in other disorders. Preferential linkage of paternal alleles has been observed for the insulin locus and type I diabetes ${ }^{91}$, and HLA alleles for selective IgA deficiency ${ }^{87}$, indicating that the mechanisms responsible for these findings may be common to several disorders.

Mono-allelic expression has been identified for a number of cytokines $^{92}$ and allelic exclusion is a feature of T-cell antigen receptor (TCR) alleles expressed in individual cells. These phenomena are probably the result of the need for individual cells to commit to a consistent pattern of cytokine production. So far there is no evidence that the expressed allele derives preferentially from one parent or another. It is possible however, that the bias to one parent or another may be incomplete, or that it is most marked at a critical period in development of the immune system.

The maternal effect therefore seems deserving of further study, as it will throw light on the pathogenesis of allergic disease, and could also show a great deal in general about the nature of immunological reactions between mother and child.

\section{Conclusions}

The mechanisms of asthma, eczema and atopy follow from interactions between a system that has evolved to deal with parasitic and other infections, and a limited number of ubiquitous airborne protein antigens. Allergic diseases are a feature of westernized societies, and possibly result from reductions in the nature and frequency of childhood infections. Progress is being made in defining the genetic basis of asthma and atopy, with the hope of better classification and new treatments of disease. The relevance of some genes and genetic regions have been established, several of which may be active in other inflammatory diseases. Events early in life seem critical, and the development of atopy is fostered by the mother's strained immunological relationship with the fetus.

William Cookson is at the Wellcome Trust Centre for Human Genetics, Roosevelt Drive, Headington, Oxford OX3 7BN, UK (e-mail: william.cookson@ndm. ox.ac.uk).

\footnotetext{
1. von Pirquet, C. Allergie. Münch. med. Wochenschr. 30, 1457 (1906).

2. Coca, A. F. \& Cooke, R. A. On the phenomenon of hypersensitiveness. J. Immunol. 8, 163-182 (1923). 3. Smith, D. H. et al. A national estimate of the economic costs of asthma. Am. J. Respir. Crit. Care Med. 156, 787-793 (1997).

4. Nowak, D., Volmer, T. \& Wettengel, R. Asthma bronchiale—eine Krankheitskostenanalyse. Pneumologie 50, 364-371 (1996).

5. National Asthma Campaign. Asthma Agenda (National Asthma Campaign, London, 1998).

6. Stuart, M. Start-up 12-20 (April 1999).

7. Sampson, H. A. Pathogenesis of eczema. Clin. Exp. Allergy 20, 459-467 (1990).

8. Schultz-Larsen, F. A genetic-epidemiologic study in a population-based twin sample. J. Am. Acad. Dermatol. 28, 719-723 (1993).

9. Cox, H. E. et al. Association of atopic dermatitis to the beta subunit of the high affinity Immunoglobulin E receptor. Br. J. Dermatol. 138, 182-187 (1998).
} 
10. Moffatt, M. F. \& Cookson, W. O. C. M. in Genetics of Asthma and Atopy (ed. Hall, I. P. ) (Monogr. Allergy 33, 71-97) (Karger, Basel, 1996).

11. Larsen, J. N., Sparholt, S. H. \& Ipsen, H. Epitope structure of recombinant isoallergens of Bet v 1. J. Adv. Exp. Med. Biol. 409, 243-249 (1996).

12. Mueller, G. A., Benjamin, D. C., Rule, G. S. \& Beirne, B. Tertiary structure of the major house dust mite allergen Der p 2: sequential and structural homologies. Biochemistry 37, 12707-12714 (1998).

13. Sigurs, N. et al. Appearance of atopic disease in relation to serum IgE antibodies in children followed up from birth for 4 to 15 years. J. Allergy Clin. Immunol. 94, 757-763 (1994).

14. Rona, R. J., Chinn, S. \& Burney, P. G. Trends in the prevalence of asthma in Scottish and English primary school children 1982-92. Thorax 50, 992-993 (1995).

15. Aberg, N., Hesselmar, B., Aberg, B. \& Eriksson, B. Increase of asthma, allergic rhinitis and eczema in Swedish schoolchildren between 1979 and 1991. Clin. Exp. Allergy 25, 815-819 (1995).

16. Dubois, P., Degrave, E. \& Vandenplas, O. Asthma and airway hyperresponsiveness among Belgian conscripts, 1978-91. Thorax 53, 101-105 (1998).

17. von Mutius, E., Fritzsch, C., Weiland, S. K., Roll, G. \& Magnussen, H. Prevalence of asthma and allergic disorders among children in united Germany: a descriptive comparison. Brit. Med. J. 305, 1395-1399 (1992).

18. von Mutius, E. et al. Prevalence of asthma and atopy in two areas of West and East Germany. Am. J. Respir. Crit. Care Med. 149, 358-364 (1994).

19. Bjorksten, B. et al. Prevalence of childhood asthma, rhinitis and eczema in Scandinavia and Eastern Europe. Eur. Respir. J. 12, 432-437 (1998).

20. von Mutius, E., Weiland, S. K., Fritzsch, C., Duhme, H. \& Keil, U. Increasing prevalence of hay fever and atopy among children in Leipzig, East Germany. Lancet 351, 862-866 (1998).

21. The International Study of Asthma and Allergies in Childhood (ISAAC) Steering Committee. Worldwide variation in prevalence of symptoms of asthma, allergic rhinoconjunctivitis, and atopic eczema. Lancet 351, 1225-1232 (1998).

22. European Community Respiratory Health Survey (ECRHS). Variations in the prevalence of respiratory symptoms, self-reported asthma attacks, and use of asthma medication in the European Community Respiratory Health Survey (ECRHS). Eur. Respir. J. 9, 687-695 (1996).

23. Von Ehrenstein, O., von Mutius, E., Illi, S., Hachmeister, A. \& von Kries, R. Reduced prevalence of atopic diseases in children living on a farm. Epidemiology 9, S118 (1998).

24. Godfrey, R. C. Asthma and IgE levels in rural and urban communities of The Gambia. Clin. Allergy 5 , 201-207 (1975)

25. Braun-Fahrländer, C. et al. Prevalence of hay fever and allergic sensitization in farmer's children and their peers living in the same rural community. Clin. Exp. Allergy 29, 28-34 (1999).

26. Staines, C. Childhood factors and adult atopy: results from the European Community Respiratory Health Survey. Am. J. Respir. Crit. Care Med. 157, Al1 (1998)

27. von Mutius, E. et al. Skin test reactivity and number of siblings. Br. Med. J. 308, 692-695 (1994).

28. Holt, P. G., McMenamin, C. \& Nelson, D. Primary sensitisation to inhalant allergens during infancy. Pediatr. Allergy Immunol. 1, 3-15 (1990).

29. Sporik, R., Holgate, S., Platts-Mills, T. A. E. \& Cogswells, J. J. Exposure to house dust mite allergen Der p I and the development of asthma in children. N. Engl. J. Med. 323, 502-507 (1990).

30. Bjorksten, B. Allergy priming early in life. Lancet 353, 167-168 (1999).

31. Rook, G. A. \& Stanford, J. L. Give us this day our daily germs. Immunol. Today 19, 113-116 (1998).

32. Anto, J. M. \& Sunyer, J. A point-source asthma outbreak. Lancet 1, 900-903 (1986).

33. Duffy, D. L., Martin, N. G., Battistutta, D., Hopper, J. L. \& Mathews, J. D. Genetics of asthma and hay fever in Australian twins. Am. Rev. Respir. Dis. 142, 1351-1358 (1990).

34. Lawrence, S. et al. Genetic analysis of atopy and asthma as quantitative traits and ordered polychotomies. Ann. Hum. Genet. 58, 359-368 (1994).

35. Holberg, C. et al. Segregation analysis of physician-diagnosed asthma in hispanic and non-hispanic white families. Am. J. Respir. Crit. Care Med. 154, 144-150 (1996).

36. Jenkins, M., Hopper, J. \& Giles, G. Regressive logistic modelling of familial aggregation for asthma in 7,394 population-based nuclear families. Genet. Epidemiol. 14, 317-332 (1997).

37. Schultz Larsen, F., Holm, N. V. \& Henningsen, K. Atopic dermatitis. A genetic epidemiologic study in a population-based twin sample. J. Am. Acad. Derm. 15, 487-494 (1986).

38. Dold, S. et al. Genetic risk for asthma, allergic rhinitis and atopic dermatitis. Arch. Dis. Child. 67, 1018-1022 (1992)

39. Blumenthal, M. N., Namborrdiri, K., Mendell, N., Gleich, C. \& Elston, R. C. Genetic transmission of serum IgE levels. Am. J. Med. Genet. 10, 219-228 (1981).

40. Borecki, I., Rao, D. C., Lalouel, J. M., McGue, L. \& Gerrard, J. W. Demonstration of a common major gene with pleiotrophic effects on Immunoglobulin E and allergy. Genet. Epidemiol. 2, 327-338 (1985).

41. Collins, F. S. Positional cloning moves from perditional to traditional. Nature Genet. 9, 347-350 (1995)

42. Cookson, W. O. C. M., Sharp, P. A., Faux, J. A. \& Hopkin, J. M. Linkage between Immunoglobulin E responses underlying asthma and rhinitis and chromosome 11q. Lancet 8650, 1292-1295 (1989).

43. Watson, M. et al. Exclusion from proximal 1lq of a common gene with megaphenic effect on atopy. Ann. Hum. Genet. 59, 403-411 (1995).

44. Hill, M. R. \& Cookson, W. O. C. M. A new variant of the $\beta$ subunit of the high-affinity receptor for Immunoglobulin E (FceRI- $\beta$ E237G): associations with measures of atopy and bronchial hyperresponsiveness. Hum. Mol. Genet. 5, 959-962 (1996).

45. Shirakawa, T. et al. Association between atopic asthma and a coding variant of Fc epsilon RI beta in a Japanese population. Hum. Mol. Genet. 5, 1129-1130 (1996).

46. van Herwerden, L. et al. Linkage of high-affinity $\operatorname{IgE}$ receptor gene with bronchial hyperreactivity, even in absence of atopy. Lancet 346, 1262-1265 (1995).

47. Palmer, L. J. et al. FceRI- $\beta$ polymorphism and total serum IgE levels in endemically parasitised Australian Aboriginies. Am. J. Hum. Genet. 61, 182-188 (1997).

48. Shirakawa, T. S. et al. Association between atopy and variants of the $\beta$ subunit of the high-affinity immunoglobulin E receptor. Nature Genet. 7, 125-129 (1994).

49. Rosenwasser, L. J. Genetics of atopy and asthma: promoter-based candidate gene studies for IL-4. Int Arch. Allergy Immunol. 113, 61-64 (1997).

50. Baldini, M. et al. A polymorphism in the $5^{\prime}$ flanking region of the $\mathrm{CD} 14$ gene is associated with circulating soluble CD14 levels and with total serum immunoglobulin E. Am. J. Respir. Cell Mol. Biol. 20, 976-983 (1999)

51. Hershey, G. K., Friedrich, M. F., Esswein, L. A., Thomas, M. L. \& Chatila, T. A. The association of atopy with a gain-of-function mutation in the alpha subunit of the interleukin-4 receptor. N. Engl. J. Med. 337, 1720-1725 (1997)

52. Green, S. A., Turki, J., Innis, M. \& Liggett, S. Amino-terminal polymorphisms of the human $\beta_{2}$-adrenergic receptor impart distinct agonist-promoted regulatory properties. Biochemistry 33, 9414-9419 (1994)

53. Hall, I. P. Beta 2 adrenoceptor polymorphisms: are they clinically important? Thorax 51, 351-353 (1996).

54. Moffatt, M. F. \& Cookson, W. O. C. M. Tumour necrosis factor haplotypes and asthma. Hum. Molec Genet. 6, 551-554 (1997).

55. Shirakawa, T. et al. Linkage between severe atopy and chromosome 11q in Japanese families. Clin. Genet. 46, 125-129 (1994).

56. Yandava, C. N. et al. Pharmacogenetic association between ALOX5 promoter genotype and the response to anti-asthma treatment. Nature Genet. 22, 168-170 (1999).

57. Sanak, M., Simon, H. U. \& Szczeklik, A. Leukotriene C4 synthase promoter polymorphism and risk of aspirin-induced asthma. Lancet 350, 1599-1600 (1997).

58. Gyapay, G. et al. The 1993-94 Genethon human genetic linkage map. Nature Genet. 7, 246-339 (1994).

59. Lander, E. \& Kruglyak, L. Genetic dissection of complex traits: guidelines for interpreting and reporting linkage results. Nature Genet. 11, 241-247 (1995).

60. Cookson, W. O. \& Palmer, L. J. Investigating the asthma phenotype. Clin. Exp. Allergy 28(Suppl. 1), 88-89 (discussion 108-110) (1998).

61. Risch, N. \& Zhang, H. Extreme discordant sib pairs for mapping quantitative trait loci in humans. Science 268, 1584-1589 (1995).

62. Marsh, D. G. et al. Linkage analysis of IL-4 and other chromosome 5q31. 1 markers and total serum IgE concentrations. Science 264, 1152-1156 (1994).

63. Meyers, D. A. et al. Evidence for a locus regulating total serum IgE levels mapping to chromosome 5. Genomics 23, 464-470 (1994).

64. Barnes, K. C. et al. Linkage of asthma and total serum IgE concentration to markers on chromosome 12q: evidence from Afro-Caribbean and Caucasian populations. Genomics 37, 41-50 (1996).

65. Nickel, R. et al. Evidence for linkage of chromosome 12q15-q24. 1 markers to high total serum IgE concentrations in children of the German Multicenter Allergy Study. Genomics 46, 159-162 (1997)

66. Moffatt, M. F. et al. Genetic linkage of the TCR- $\alpha / \delta$ region to specific Immunoglobulin E responses. Lancet 343, 1597-1600 (1994).

67. Daniels, S. E. et al. A genome-wide search for quantitative trait loci underlying asthma. Nature 383, 247-250 (1996)

68. Eiberg, H., Lind, P., Mohr, J. \& Nielsen, L. S. Linkage relationship between the human immunoglobulin-E polymorphism and ESD marker. Cytogen. Cell. Genet. 40, 622 (1985).

69. Kimura, K. et al. Linkage and association of atopic asthma to markers on chromosome 13 in the Japanese population. Hum. Molec. Genet. 8, 1487-1490 (1999).

70. Ober, C. et al. [The Collaborative Study on the Genetics of Asthma. ] Genome-wide search for asthm susceptibility loci in a founder population. Hum. Mol. Genet. 7, 1393-1398 (1998).

71. Wjst, M. et al. [German Asthma Genetics Group. ] A genome-wide search for linkage to asthma. Genomics 58, 1-8 (1999).

72. Hizawa, N. et al. [The Collaborative Study on the Genetics of Asthma (CSGA). ] Genetic regulation of Dermatophagoides pteronyssinus-specific IgE responsiveness: a genome-wide multipoint linkage analysis in families recruited through 2 asthmatic sibs. J. Allergy Clin. Immunol. 102, 436-442 (1998)

73. The Collaborative Study on the Genetics of Asthma (CSGA). A genome-wide search for asthma susceptibility loci in ethnically diverse populations. Nature Genet. 15, 389-392 (1997).

74. Dizier, M. H. et al. Genome screen for asthma and related phenotypes in the French EGEA study. Am. J. Respir. Crit. Care Med. 159, A649 (1999).

75. Satsangi, J. et al. Two stage genome-wide search in inflammatory bowel disease provides evidence for susceptibility loci on chromosomes 3, 7 and 12. Nature Genet. 14, 199-202 (1996).

76. Hugot, J. P. et al. Mapping of a susceptibility locus for Crohn's disease on chromosome 16. Nature 379, 821-823 (1996)

77. Duerr, R. H. et al. Linkage and association between inflammatory bowel disease and a locus on chromosome 12. Am. J. Hum. Genet. 63, 95-100 (1998).

78. Mansfield, J. C. et al. Novel genetic association between ulcerative colitis and the anti-inflammatory cytokine interleukin-1 receptor antagonist. Gastroenterology 106, 637-642 (1994).

79. Hardwick, L. J. et al. Genetic mapping of susceptibility loci in the genes involved in rheumatoid arthritis. J. Rheumatol. 24, 197-198 (1997).

80. Nakagawa, Y. et al. Fine mapping of the diabetes-susceptibility locus, IDDM4, on chromosome 11q13. Am. J. Hum. Genet. 63, 547-556 (1998).

81. Ramsay, G. DNA chips: state-of-the art. Nature Biotechnol. 16, 40-44 (1998).

82. Risch, N. \& Merikangas, K. The future of genetic studies of complex human diseases. Science 273, 1516-1517 (1996).

83. Moffatt, M. F. \& Cookson, W. O. The genetics of asthma. Maternal effects in atopic disease. Clin. Exp Allergy 28(Suppl 1), 56-61 (discussion 65-66) (1998).

84. Warram, J. H., Krolewski, A. S., Gottlieb, M. S. \& Kahn, C. R. Differences in risk of insulin-dependent diabetes in offspring of diabetic mothers and diabetic fathers. N. Engl. J. Med. 311, 149-152 (1984

85. Akolkar, P. N. et al. Differences in risk of Crohn's disease in offspring of mothers and fathers with inflammatory bowel disease. Am. J. Gastroenterol. 92, 2241-2244 (1997).

86. Koumantaki, Y. et al. Family history as a risk factor for rheumatoid arthritis: a case-control study. J. Rheumatol. 24, 1522-1526 (1997).

87. Vorechovsky, I., Webster, A. D. B., Plebani, A. \& Hammarstrom, L. Genetic linkage of IgA deficiency to the major histocompatibility complex: evidence for allele segregation distortion, parent-of-origin penetrance differences, and the role of IgA antibodies in disease predisposition. Am. J. Hum. Genet. 64 , 1096-1109 (1999).

88. Hall, J. G. Genomic imprinting. Arch. Dis. Child. 65, 1013-1016 (1990).

89. Moffatt, M. F. et al. Factors confounding genetic linkage between atopy and chromosome 11q. Clin. Exp. Allergy 22, 1046-1051 (1992).

90. Moffatt, M. F., Abecasis, G., James, A., Musk, A. W. \& Cookson, W. O. C. M. Association of parental atopy phenotype with linkage to FceRI- $\beta$. Am. J. Respir. Crit. Care Med. 159, A648 (1999).

91. Bennett, S. T. \& Todd, J. A. Human type I diabetes and the insulin gene: principles of mapping polygenes. Annu. Rev. Genet. 30, 343-370 (1996).

92. Chess, A. Expansion of the allelic exclusion principle? Science 279, 2067-2068 (1998). 